\title{
Unemployment: natural rate epicycles or hysteresis?*
}

\author{
Rod Cross** \\ Department of Economics, University of Strathclyde, Glasgow, UK
}

This paper argues that the natural rate of unemployment hypothesis, in which equilibrium unemployment is determined by 'structural' variables alone, is wrong: it is both implausible and inconsistent with the evidence. Instead, equilibrium unemployment is haunted by hysteresis. The curious history of the natural rate hypothesis is considered, curious because the authors of the hypothesis thought hysteresis to be relevant. The various methods that have been used to model hysteresis in economic systems are outlined, including the Preisach model with its selective, erasable memory properties. The evidence regarding hysteresis effects on output and unemployment is then reviewed.

Keywords: unemployment, natural rate hypothesis, hysteresis

JEL codes: $B 22, C 60, E 12, E 24, E 31, N O 1$

\section{INTRODUCTION}

The flux in the popularity of economic ideas is particularly marked in relation to hysteresis. Recessions, such as those of the early 1980s, early 1990s and the post-2007 'great recession', bring a heightened interest in the idea that economic systems are haunted by hysteresis. When recoveries from recession occur, interest in hysteresis tends to abate, even though the evidence is that the output losses associated with recessions have a permanent component (Cerra/Saxena 2008).

The term 'hysteresis', from the Greek 'to be behind', was coined for application to scientific phenomena in relation to the experimental evidence obtained by twisting iron and steel wires when magnetised, or magnetising them when twisted:

$\ldots$ when the wire, after being normally polarised at $+\theta^{\circ}$, is twisted over to $-\theta^{\circ}$, the polarisation does not change to the full normal value for $-\theta^{\circ}$, but to something less, and this difference becomes still more apparent after several twistings from one side to the other ... by dividing the full twist across into several steps, cyclical curves have been obtained, showing the relation of polarisation to torsion when the same magnetising force is kept up without interruption or reversal ... these curves exhibit, in a striking manner, a

\footnotetext{
* Keynote address to the FMM conference on 'The jobs crisis: causes, cures, constraints macroeconomic policy, unemployment and hysteresis', Berlin, Germany, 24-26 October 2013. ** Contact details: Department of Economics, University of Strathclyde, Sir William Duncan Building, 130 Rottenrow, Glasgow G4 0LN, Scotland, UK; email: rod.cross@strath.ac.uk. The author is grateful to Milton Friedman for having granted permission to quote from private correspondence; to Michael Grinfeld for useful discussion; to Andrew Watt for helpful comments; and to Mary McAuley for typing this paper.
} 
persistence of previous state, such as might be caused by molecular friction ... the curves for the back and forth twists are irreversible, and include a wide area between them ... to this action ... the author now gives the name Hysteresis. (Ewing 1881: 22)

Although hysteresis curves are not reversible, in the sense that the system does not retrace its steps when a force is applied and removed, it is clear from the original context that hysteresis applies in both directions. Thus the bad news story of hysteresis curses arising from recessions is matched by a good news story whereby hysteresis brings blessings, in the form of lasting benefits, when economies reach peaks in economic activity. Yet little tends to be heard about hysteresis during booms in economic activity. This puzzle may be attributed to 'loss aversion' (Kahneman/Tversky 1979), whereby the costs of recessions are weighted more than the benefits of booms in economic activity. Or, this tendency might be simply down to the fixation of mainstream economics with a simplistic neoclassical notion of equilibrium, in which the trend time path for output is invariant to cyclical fluctuations. Growing economies eventually experience levels of output that surpass the pre-recession peak, allowing economists afflicted by 'cognitive dissonance' (Akerlof/Dickens 1982) to conflate the beneficial effects of booms in economic activity with those of 'equilibrium' growth, so as not to have their belief in neoclassical equilibrium - a fixed point or time path - disturbed.

The tendency in mainstream economics to think of recessions as temporary aberrations is matched by a tendency to see financial crises as exceptional rather than endemic. Economic history suggests that financial crises, including the build-up phases and the aftermaths, are more the rule than the exception, as documented in Kindleberger/Aliber (6th edn, 2011). The jacket cover for the 5th edition of this classic text (2005) has the prophetic quote from Samuelson: 'Sometime in the next five years you may kick yourself for not reading and re-reading Kindleberger's Manias, Panics and Crashes'. The financial crisis that started to explode with the 'credit crunch' of 2007 was seen by some economists as reflecting 'a systemic failure of the economics profession' (Colander et al. 2009: 1). Whereas to a mainstream economist such as Lucas (2009), the challenge to the efficient markets hypothesis was merely part of 'a flood of criticism which has mainly served to confirm the accuracy of the hypothesis ... over the years exceptions and "anomalies" have been discovered ... but for the purposes of macroeconomic analysis and forecasting these departures are too small to matter'. This reaction from mainstream economists is akin to arguing that Russian roulette is normally a safe game to play.

In Section 2 of this paper, the curious case of how the natural rate of unemployment hypothesis came to be established as conventional wisdom in mainstream economics is discussed, curious because both the originators of this hypothesis took hysteresis to be relevant. Section 3 considers different methods of modelling hysteresis in economic systems. In Section 4, the evidence regarding hysteresis effects on unemployment and output is discussed. Section 5 offers some concluding remarks.

\section{NATURAL AND NURTURAL UNEMPLOYMENT}

The natural rate of unemployment hypothesis (NRUH) can be expressed as follows:

$$
\begin{gathered}
\ddot{p}=f\left(u-u^{*}\right) \text { with } f^{\prime}\left(u-u^{*}\right)<0 \text { and } f(0)=0 \\
\qquad u^{*}=g(z) \\
u^{*} A u .
\end{gathered}
$$


Here, $p$ is the log of the price level, a dot indicates a time derivative, $u$ is the actual unemployment rate, $u^{*}$ is the natural rate, $z$ is a vector of 'structural' variables, such as unemployment benefits relative to wages, and $A$ indicates 'acts as an attractor for'. Links to aggregate output can be added by specifying Okun's-law-type relationships between $u$ and $y$, and between $u^{*}$ and $y^{*}$, where $y$ and $y^{*}$ are the actual and natural levels of aggregate output.

This is the neat formulation of the NRUH that came to be the conventional wisdom in mainstream economics quite soon after the hypothesis was formulated by Phelps (1967) and Friedman (1968). The famous definition is that $u^{*}$ is determined by 'the actual structural characteristics of the labour and commodity markets, including market imperfections, stochastic variability in demands and supplies, the cost of gathering information about job vacancies and labour availabilities, the costs of mobility, and so on' (Friedman 1968: 8). The policy message was that sustainable reductions in unemployment could only be achieved by micro policy interventions on the 'structural characteristics of labour and commodity markets', the $z$ variables, and not by macro policies. Pace Keynes, macro policies could only influence $u$ or $y$, and $\left(u-u^{*}\right)$ or $\left(y-y^{*}\right)$ gaps would be associated with rising or falling rates of inflation, which would be unsustainable. When inflation targets came into fashion in the early 1990s, this framework gave rise to the Taylor rule as to how central banks should set interest rates in order to achieve a target rate of inflation.

We will consider the question of whether the NRUH is consistent with the evidence in Section 4 of this paper. Here, the issue of the plausibility of the hypothesis is considered. One implausibility is that $u^{*}$ is independent of the steady rate of inflation. Why bother whether the steady rate of inflation is -2 per cent, +2 per cent, +4 per cent,+10 per cent or +1000 per cent if $u^{*}$ and $y^{*}$ are the same? The evidence suggests that $u^{*}$ tends to rise as steady rates of inflation fall below about 4 per cent (Akerlof et al. 2000; Blanchard et al. 2010; Ball 2013); and that there are serious deleterious effects on the 'real' economy from inflation rates in excess of about 20 per cent (Barro 1997). Another implausibility is that the $z$ variables are not affected by macro policies. If, for example, unemployment benefits or minimum wages are not fully indexed to a relevant cost of living index, their real values will change with the rate of inflation, and so would $u^{*}$.

Economists often argue on the basis of the authority of leading figures in their discipline. In this respect, the history of how the NRUH came to be adopted as conventional wisdom is curious. The NRUH apparently rules out hysteresis effects, whereby changes in actual unemployment lead to changes in the equilibrium rate. What did the co-originators of the natural rate doctrine have to say on the hysteresis issue?

With Phelps (1972, p xxiii) we have: '... the transition from one equilibrium to the other tends to have long lingering effects on the labour force, and these effects may be discernible on the equilibrium rate of unemployment for a long time ... the natural rate ... at any future date will depend on the course of history in the interim ... such a property is often called hysteresis'. In later work, Phelps has continued to consider hysteresis as relevant to labour markets, but has tended to see 'ratchet effects' on equilibrium unemployment as being due to slowly decaying effects of oil price and real interest rate shocks: '... even if there are instances in which hysteresis was of quantitative importance, the evidence does not suggest that this importance is at all widespread' (Phelps 1995: 228).

Even more curious is what Friedman had to say on the subject of hysteresis:

I do not regard the natural rate hypothesis and the hysteresis hypothesis as in any way fundamentally incompatible hypotheses. The hysteresis hypothesis is simply a more sophisticated form of the natural rate hypothesis, and as such I have no doubt that it may well have a good deal of truth to it. It never has seemed to me that a crucial element of the natural rate hypothesis was a belief 
that the final equilibrium was independent of the path by which it was reached. Its crucial element it seems to me is a very different one. It is that nominal magnitudes must be sharply distinguished from real magnitudes, and that nominal magnitudes in and of themselves cannot determine real magnitudes. In applying this, it is necessary to recognise that the rate of change of the quantity of money or of prices is not a nominal magnitude in the sense that it is dependent on arbitrary units in the same sense that the stock of money is or the level of prices. (Friedman, 2 November 1990, letter to the author)

In the same letter, Friedman highlighted Marshall's acknowledgement of the importance of hysteresis in economic systems:

I was struck with one feature of your discussion of the history of thought and the concept of equilibrium. You cite Schumpeter's comments in 1934 as an early precursor to the hysteresis notion. That clearly is wrong. Alfred Marshall, in the first edition of his Principles (1890), writes: 'The chief cause of this divergence is the fact that, if the normal production of a commodity increases and afterwards again diminishes to its old amount, the demand price and supply price are not likely to return, as the pure theory assumes they will, to their old positions for that amount' (Marshall 1890, 1st ed., pp. 425-426).

So it is clear that both of the originators of the NRUH thought that equilibrium unemployment would be influenced by the time path of actual unemployment, as well as by 'structural' factors. This is an 'NNRUH', equilibrium unemployment being determined by nurture as well as by nature. The puzzle, then, is why the primitive NRUH came to dominate seminar room and policy discussion.

\section{MODELLING HYSTERESIS IN ECONOMIC SYSTEMS}

As his biographer son commented, Ewing coined the term hysteresis 'feeling the need of a word that should be sufficiently wide to include, not only the phenomena of magnetic retentiveness, but other manifestations of what seemed to be essentially the same thing' (Ewing 1939: 62). The assessor for the Royal Society paper in which Ewing coined the term, Sir William Thomson (later Lord Kelvin), initially insisted that the phrase 'effects of retentiveness' - Elastische Nachwirkung was a German phrase used in the literature of the time - be used instead. Ewing stuck to his term, sensing that effects that remained after their initial causes are removed would be relevant to a wider range of phenomena than just those involving electromagnetic fields in ferric metals. Arguably, applying the notion of hysteresis to economic systems would have helped Keynes in his 'struggle to escape' from the tenets of (neo)classical economics. Ewing was a professor of mechanism and applied mechanics at the University of Cambridge, 1890-1903, where he established engineering as an academic discipline. He retained an honorary fellowship at King's College during his later career at the Admiralty, where he was head of the Room 40 signals intercept and decoding group during World War I, and as Principal of the University of Edinburgh. The only biographical record of contact with Keynes, however, comes in 1933: 'Ewing spent much of his time at King's College, where Maynard Keynes provided those at the high table with interesting ideas about the Economic Conference, on which pessimistic views were general' (Ewing 1939: 277). It would take a playwright of Tom Stoppard's calibre to reconstruct a conversation that might have taken place between the two great men. What can be said is that key aspects of hysteresis - non-reversibility, remanence and heterostasis - would not have been alien to Keynes's General Theory (1936) depiction of the lack of self-adjustment in economic systems. 


\subsection{Simple hysteresis}

The simplest way to introduce hysteresis into the determination of equilibrium unemployment is to allow $u$ to help determine $u^{*}$. Changes in $u$ tend to be dominated by changes in the rates of outflow from unemployment into employment rather than by changes in the rates of inflow from employment into unemployment. Thus, with a shortish time lag, changes in $u$ are associated with changes in the proportion of the unemployed who have been so for a long spell, say longer than 6 months. Long spells of unemployment tend to reduce the employability of those affected, so changing the 'structural' characteristics of the labour force. Hargreaves Heap (1980) and Cross (1980) put forward simple models that attempted to incorporate such effects. In contrast to the NRUH specification that

$$
\dot{u}^{*}=g(\dot{z}),
$$

we could have:

$$
\dot{u}^{*}=g(\dot{z})+a \dot{u} \quad \text { with } \quad a>0
$$

or

$$
\dot{u}^{*}=g(\dot{z})+b\left(u-u^{*}\right) \quad \text { with } \quad b>0 .
$$

Equations (5) and (6) are simple ways of introducing the 'nurtural' effects of the experience of actual and long-term unemployment into the determination of 'equilibrium' unemployment. These modifications were plausible, backed by evidence on unemployment duration and re-employment probabilities (for example, McGregor 1978), and proved able to explain in a stylised way the upward ratchets in unemployment experienced by several countries in the 1980s. They, however, did not catch on amongst the Econ (Leijonhufvud 1973), a profession obsessed with representative agent microfoundations in which the different unemployment experiences of different workers cannot be accommodated.

Evidence that the relationship between $u$ and $u^{*}$ is not a simple linear one can be found in the work of Ball (1999; 2009). Ball's starting point is:

$$
u^{*}=(1-c) u_{-1}^{*}+c u_{-1},
$$

where $c$ indicates the degree of hysteresis. This is the same specification used in Hargreaves Heap (1980, equ. 4). Ball (2009: 24) finds that 'it's clear that no such linear relationship exists ... changes in $u$ sometimes cause changes in $u^{*}$ and sometimes don't ... it seems to depend on the past history of $u^{*}$ and the length of time that $u$ is pushed away from $u^{*} \ldots$ hysteresis also appears asymmetric ... e.g. an inflation run-up means it's very likely $u^{*}$ is falling, while disinflations often occur without $u^{*}$ rising'.

\subsection{Short-run NAIRUs}

An influential reformulation of the NRU as a NAIRU (Non-Accelerating Inflation Rate of Unemployment) includes 'partial' hysteresis, with unemployment reverting to the NRU in the long run: '.. there is short-term "hysteresis", in the sense that past events affect the current short-run NAIRU - but there is no long-term "hysteresis": there is a unique long-run NAIRU ... in the end the unemployment rate always reverts' (Layard et al. 1991: 10). This framework forms the bedrock of a widely used macroeconomics text 
(Carlin/Soskice 1990), and it plays a key role in the forward guidance for the setting of interest rates introduced by the Bank of England in August 2013 (Bank of England 2013a; 2013b).

Whilst there is a substantial body of evidence that the long-term unemployed exert little pressure on wages (Nickell 1987, for example), there is little evidence of cointegration between 'structural' variables and unemployment (Jenkinson 1988; Darby/Wren-Lewis 1993). A key issue is whether the above-cited claim that in the end the unemployment rate always reverts is correct. Cross/Lang (2011) show that such reversion does not occur in this model, and that convergence to a unique long-term unemployment proportion of the NRU does not occur, given the estimated parameter values. Cross/Lang regard the NAIRU as Not An Interesting Rate of Unemployment. Such issues have been off the radar in most of the voluminous NAIRU literature.

\subsection{Unit roots}

Perhaps the most widely known model of hysteresis in unemployment is that of Blanchard/Summers (1986a; 1986b). The microfoundations are provided by an insider-outsider' view of labour markets in which wages are negotiated to try and ensure continued employment of the currently employed 'insiders', with those who become unemployed becoming 'outsiders', disenfranchised from wage negotiations. If wages are negotiated caring only about the workers employed at the start of the bargaining period, the outcome is:

$$
n=n_{-1}+\epsilon,
$$

where $n$ is the log of employment and $\epsilon$ is an unexpected innovation in aggregate demand (Blanchard/Summers 1986b: 5, equ. 5). This means that 'for a given labour force, equilibrium unemployment is equal to the last period's value of actual unemployment ... the economy shows no tendency to return to any fixed equilibrium value ... after an adverse shock which reduces employment, workers who are still employed have no desire to cut the nominal wage so as to increase employment ... after a favourable shock which increases employment, some outsiders are now employed and will have no desire to increase wages and to price themselves out of employment' (ibid.: 5). In statistical terms, unemployment has a unit root.

In recent contributions, both Blanchard and Summers have produced evidence that fiscal multipliers were higher in the post-2007 'great recession', in the range 0.9-1.7, than previous estimates, typically 0.5, suggested. The October 2012 World Economic Outlook of the IMF reported a significant negative relationship between fiscal consolidation forecasts and subsequent forecast errors regarding GDP and unemployment (IMF 2012: 41-43, box 1.1). If the forecasters had, at least on average, a 'correct' model, the coefficient on the fiscal consolidation forecast should have been zero (Blanchard/Leigh 2013: 3). As deLong/Summers (2012) point out, the downward revisions of these forecasts for potential GDP during the 'great recession' implicitly involve hysteresis. 'Economic forecasters' revisions of their projections of the US economy over the next decade certainly incorporate hysteresis effects into their projections' (ibid.: 32). In their paper, an explicit form of hysteresis is modelled by a relationship $\Delta Y_{f}=\eta \Delta Y_{n}$, where $Y_{f}$ is future output, which is taken to be supply determined, $Y_{n}$ is present output, and $\eta$ is a parameter indicating the degree of hysteresis, measured in inverse years. Hysteresis arises from both physical capital and labour market effects of recessions. There can also be institutional channels for hysteresis (Blanchard 2005). 


\subsection{Preisach models of hysteresis}

Since the early 1990s (Cross 1993; Amable et al. 1995), a small group of economists have applied more formal mathematical methods of analysing economic systems with hysteresis. These methods involve the systems theory generalisation (Krasnosel'skii/Pokrovskii 1989) of the original Preisach (1935) model of electromagnetic hysteresis, making particular use of the Mayergoyz (1991) geometric representation of this analysis. For a comprehensive account of the mathematical literature, see Bertotti/Mayergoyz (2006); and for surveys of applications to economic systems, see Göcke (2002) and Cross et al. (2009).

The simplest version of the Preisach model is scalar and involves 'non-ideal' or 'lazy' relays connecting an input variable to an output variable. The following exposition is based on a 'real options' approach to the determination of economic activity (Piscitelli et al. 1999) that uses the Preisach framework to model the equilibrium unemployment rate that is consistent with a steady rate of inflation. Discontinuous adjustment and inertia characterise much of economic activity. Firms only go ahead with investment projects when hurdle rates of return exceed three or four times the cost of capital, and often absorb operating losses for lengthy periods before abandoning investments (Dixit 1992). The rationale is that investments involve sunk costs that cannot be recouped should the projects be abandoned; intractable uncertainty regarding the future returns on investments means that the delaying of decisions allows more information to be revealed; and decisions are not just about whether to invest or exit, but when to do so. Labour is a quasi-fixed factor of production, so hiring or redundancy decisions are inextricably linked to the decision on investment and thus share many of the characteristics of physical investment decisions (Oi 1962). Preisach-type models have distinct upper and lower triggers for going ahead with, and for abandoning, investments in physical capital or labour. Inertia occurs when returns are in between the entry and exit triggers. In this zone, firms can be active or inactive depending on whether the zone has been approached from above or below. Thus the history of the past state of economic activity has to be taken into account in order to explain the present level of economic activity.

There are $M$ potential operational units which, when active, produce one unit of output and employ one unit of labour; when inactive, the units produce and employ zero. The number of active operational units is $N$. Each unit is characterised by a hysteresis operator $F_{a b}$, with the $a$ and $b$ switching triggers differing between operational units because of differences in sunk costs, uncertainty and the potential value of waiting to acquire more information. A unit requires a market price of $p \geq a$ in order to become active, and a price of $p \leq b$ to exit and become inactive. Hence the 'lazy' relays relating the market price to economic activity or inactivity. In the range $b<p<a$, an operational unit can be either active or inactive depending on its previously acquired propensity, which turns on whether this range has been approached from above or below.

The market price is specified as:

$$
p_{t}=x_{t} f\left(q_{t-1}\right),
$$

where $x$ is an aggregate demand shock, and $f(q)$ is the deterministic component of the inverse demand function, with $q_{t-1}=N_{t-1} / M$. The dynamics of (9) turn on how $p_{t+1}$ determines $q_{t+1}$, which can be written as:

$$
q_{t+1}=\frac{1}{M} \sum_{i=1}^{M} F_{a_{i} b_{i}}\left(x_{t+1} f\left(q_{t}\right)\right) .
$$

This specification of economic activity, as being determined by non-linear responses to aggregate shocks by heterogeneous units, yields the remanence and selective memory properties of Preisach models of hysteresis. Economic activity is determined not just by the 
current value of the aggregate shock variable, but also by the non-dominated extremum values that have been experienced - that is, larger subsequent extremum values wiping out the memory of smaller previous extrema. Thus the largest contractionary shock experienced, and any subsequent declining sequence of local extremum values, will retain an influence, until superseded by larger shocks; and similarly with expansionary shocks. Bygones are not bygones (see Mayergoyz 1991, for a formal proof; and Cross 1993, for an economic application).

An account of an equilibrium unemployment rate that is haunted by a selective memory of the extremum values of aggregate shocks can be derived from the relationship $q_{t}=$ $N_{t} / M$. The rate of inactivity is $(M-N) / M$. Use this as a proxy for unemployment:

$$
u=(M-N) / M \text {. }
$$

So equations (1), (2) and (3) for the NRUH are replaced by:

$$
\begin{aligned}
\ddot{p} & =f\left(u-u h^{*}\right) . \\
u & =g(z, x) \\
u h^{*} & =h(z, h(x)),
\end{aligned}
$$

where $u b^{*}$ is the hysteresis-haunted equilibrium rate of unemployment and $h(x)$ is a hysteresis index of past shocks to aggregate demand. To compute the $h(x)$ index for some aggregate demand shock variable, such as 'the' interest rate, exchange rate or oil price, requires specifying a Preisach weight function $w(a, b)$ describing the way the $F_{a b}$ hysteresis operators are distributed amongst operational units. There is a problem here, in that data on such switching values are not readily available. In some contexts, however, the selective memory, or 'wiping out', properties are not sensitive to the choice of the Preisach weight function (see Mayergoyz 1991: ch.1, for discussion). Darby et al. (2006: 677-685) experimented with normal, Poisson and exponential distribution specifications of $w(a, b)$ for economic time series, and found that the hysteresis index was not particularly sensitive to the distributional assumption used.

This hysteresis-haunted specification of equilibrium unemployment has, for any given set of structural variables $\bar{z}$, a range of 'equilibrium' unemployment rates - 'equilibrium' in the sense of being consistent with steady inflation. Whether it is a high or low equilibrium unemployment rate will be determined by the non-dominated extremum values of the shocks to aggregate demand that have been experienced (see Darby et al. 2006: 676, fig. 8.6). The idea that the last major recessions and booms leave a legacy is not implausible, given the scarring effects of recessions on labour and capital, and the beneficial effects of booms. The evidence in terms of cointegration tests is encouraging. On UK data for 1959-1996, unemployment was found to be cointegrated with a vector of variables containing a $z$ variable, the unemployment benefit replacement rate, and hysteresis indices for the nominal exchange rate, real interest rate and real price of oil (Darby et al. 2006).

\section{EVIDENCE ON HYSTERESIS IN ECONOMIC SYSTEMS}

In 1934, Keynes chose 'Is the economic system self-adjusting?' as his title for a radio talk on the pressing economic issues of the day (Keynes 1934). The negative answer to this question given by Keynes contrasts with the positive answer provided by 'neoclassical 
synthesis' and new Keynesian-DSGE models. In these mainstream models, recessions and booms are taken to be cyclical fluctuations around growth paths unaffected by the deviations from the growth path. If hysteresis effects are present, recessions and booms would have lasting effects on the level, and maybe on the growth rate, of economic activity. What does the evidence suggest?

\subsection{Partial output recoveries}

In the Friedman (1993) 'plucking' model of the business cycle, output is 'plucked' below trend at random intervals and to various extents. In each episode, the return to trend mirrors the previous fall. Capital per effective worker falls below its steady state level in a recession and, given diminishing returns to capital, the higher marginal productivity of capital generates an investment spurt that fuels the return to trend output. Hamilton (1989) tested this approach against alternative specifications, such as that there is a Markov process whereby an economy switches between positive and negative drift terms for output in 'normal' times and recessions. This proved to be best empirical fit to US GNP data post-1945. Contra the 'plucking' model, 'the estimated parameter values suggest that a typical economic recession is associated with a 3\% permanent drop in the level of GNP' (Hamilton 1989: 357). Using more informal methods, Dow estimated that the 1973-1975, 1979-1982 and 1989-1993 recessions in the UK displaced capacity output downwards by 2.2 per cent, 5.3 per cent and 8.4 per cent respectively (Dow 1998: 385-386).

More comprehensive evidence is provided by the Cerra/Saxena (2008) study of the recoveries from recessions arising from financial and political crises in 190 countries over the period 1960-2001. Impulse-response functions are estimated from:

$$
\dot{y}_{i, t}=a_{i}+\sum_{j=1}^{4} b_{j} \dot{y}_{i, t-j}+\sum_{s=0}^{4} c_{s} D_{i, t-s}+\epsilon_{i, t},
$$

where $y$ is the $\log$ of real GDP, $D$ is a dummy variable for each financial or political crisis, $i$ indicates the country, and $j$ and $s$ give the number of time lags. Taking the impulseresponse function at a 10 -year time horizon, 'the magnitude of persistent output loss ranges from around 4 per cent to 16 per cent for the various shocks' (Cerra/Saxena 2008: 456), with high income, upper-middle income and transition countries being at the top end of the range at just less than a 15 per cent permanent output loss (ibid.: 444). As with many estimates in economics, there needs to be an accuracy warning. For high income countries, for example, the 95 per cent confidence interval around the 15 per cent permanent output loss estimate is $10-20$ per cent.

\subsection{NAIRU tests}

Many countries, such as the UK, saw an upward shift in unemployment in the early 1980s recession that persisted long after the recovery from this recession. If NRUH held, this upward shift would have been accompanied by an upward ratchet in the $z$ 'structural' variables that are taken to determine $u^{*}$ (see Nickell et al. 2005, for evidence). In the UK, however, the $z$ variables that changed tended to move in a downward direction in the face of the market flexibility reforms of the Conservative government. As noted earlier, cointegration tests have, by and large, failed to find the cointegrating vectors that the NRUH implies (Jenkinson 1988; and Darby/Wren-Lewis 1993, for example). 
Even in the US, which is often seen as more fertile ground on which to find evidence in support of the NRUH, cointegration evidence has been notable for its absence. Instead, the tendency has been to model the variation over time of the NAIRU by a flexible polynomial or spline. In such models, the NAIRU is specified as a ratio between estimated coefficients, so a non-standard approach to estimating confidence intervals is required. Staiger et al. (1997) used the Fieller method to estimate such confidence intervals on US data, 1961-1995. The striking finding is that 'the 95 percent confidence intervals are wide enough to include most observed values of unemployment, with the exception of some cyclical peaks and troughs' (ibid.: 38). As the authors point out (ibid.: 47), 'an extreme conclusion to draw from these results would be that a natural rate does not exist ... a theoretical justification for such a position could be that the hysteresis that has been proposed as a description of European unemployment ... is present in the US economy as well, so there is no rate of unemployment that is in general consistent with constant inflation'. The authors do not draw this conclusion, but others might, and have (Farmer 2013).

\subsection{The return of demand}

The Ball (1999) study used OECD estimates of NAIRUs in 20 countries for the 1979-1988 period to see if 'structural' variables needed to be augmented by monetary policy variables to explain the cross-country distribution of changes in the NAIRU. The only significant 'structural' variable proved to be the duration of unemployment benefits (DUB). The amount of monetary easing (ME) at the onset of recession, measured by the cumulative decrease in 'the' real interest rate during the first year of the recession, also proved to be significant in explaining $\triangle N A I R U$, the change in the NAIRU from the pre-recession peak to 5 years afterwards. The estimated regression was:

$$
\Delta N A I R U_{i}=1.18-0.42 M E_{i}+0.64 D U B_{i}
$$

where $i=1,2 \ldots 20$ indicates the country, standard errors are given in brackets, and $R^{2}=0.43$ (Ball 1999: 207, table 5).

The Preisach models of hysteresis in unemployment, reviewed in Section 3 of this paper, are designed to take account of the non-linearities in the responses by economic agents to the shocks affecting economic systems. The selective memory property of Preisach models, whereby only the non-dominated extremum values of the shocks experienced continue to exert an influence, has echoes in the peaks and troughs used in the Ball analysis of hysteresis. Using hysteresis indices $h(x)$ to measure the influence that some shock variable $x$ continues to exert, Darby et al. (2006: 685) identified the following cointegration vector for UK unemployment, 1959-1996:

$$
\begin{aligned}
u= & 2.30 R E P R-11.60 h(N E R)+0.0047 h(R R) \\
& (0.42) \quad(2.00) \\
& +3.87 h(\text { RPOIL }),
\end{aligned}
$$

where $u$ is the log of the actual unemployment rate, $N E R$ is the nominal effective exchange rate, $R E P R$ is the replacement ratio for unemployment benefits, $R R$ is 'the' real interest rate, $R P O I L$ is the log of the real price of oil, and standard errors are given in brackets below the 
estimated coefficients. This evidence indicates that the variables invoked by the NRUH, in this case the REPR, need to be augmented by variables that capture the hysteresis effects of past demand and supply shocks in order to identify cointegation vectors for unemployment.

\section{CONCLUDING REMARKS}

The NRUH is curious in that Phelps and Friedman, who coined the natural rate hypothesis, both thought hysteresis effects to be relevant. If hysteresis effects are present, nurture, in the form of the reactions of economic agents to macroeconomic policy and other shocks, as well as nature, in the form of 'structural' variables indexing market flexibility, help determine the equilibrium unemployment rate. The evidence is that 'structural' variables can explain relatively little of the major shifts in equilibrium unemployment rates, those consistent with steady inflation, that have been observed. Attempts to patch up the natural rate hypothesis to fit the data involve 'epicycles', either in the form of unspecified forces leading natural rates to change over time, or in the form of ad hoc invocations of 'partial' hysteresis effects that would disappear in a natural rate equilibrium golden age. As Solow (1987: S33) put it, 'a natural rate that hops around from one triennium to another under the influence of unspecified forces, including past unemployment rates, is not "natural" at all ... "epiphenomenal" would be a better adjective'. Or take Blinder (1987: 132): ' $\ldots$ a theory that allows the natural rate to trundle along after the actual rate is not a natural rate theory'.

It is ironic that macroeconomics, whose foundations as an academic discipline owe much to the concerns about the high unemployment rates experienced between the two world wars of the twentieth century, started the twenty-first century with a mainstream new KeynesianDSGE model that, because of its representative agent microfoundations, can only talk about the number of hours worked by that agent, and not about the number of people who are unemployed. To have an account of unemployment, macroeconomics needs to have heterogeneous agents in its models. Preisach-type models, in which economic agents respond non-linearly to shocks, provide such foundations. The models currently available have their limitations, but progress can be made in overcoming at least some of these difficulties if the economics profession places fitting the facts over the ideology of representative agent microfoundations (Kirman 1992; 2011) when allocating research resources.

\section{REFERENCES}

Akerlof, G.A., Dickens, W.T. (1982): The economic consequences of cognitive dissonance, in: American Economic Review, 72(3), 307-319.

Akerlof, G.A., Dickens, W.T., Perry, G.L. (2000): Near rational wage and price setting and the optimal rates of inflation and unemployment, in: Brookings Papers on Economic Activity, 1, 1-60.

Amable, B., Henry, J., Lordon, F., Topol, R. (1995): Hysteresis revisited: a methodological approach, in: Cross, R. (ed.), The Natural Rate of Unemployment, Cambridge, UK: Cambridge University Press, 153-180.

Ball, L. (1999): Aggregate demand and long-run unemployment, in: Brookings Papers on Economic Activity, 2, 189-236.

Ball, L. (2009): Hysteresis in unemployment: old and new evidence, National Bureau of Economic Research Working Paper 14818, March, Cambridge, MA.

Ball, L. (2013): The case for four per cent inflation, Mimeo, Johns Hopkins University, April.

Bank of England (2013a): Monetary policy trade-offs and forward guidance, Monetary Policy Committee, August, London, UK.

Bank of England (2013b): Inflation report, Monetary Policy Committee, August, London, UK. 
Barro, R.K. (1997): Determinants of Economic Growth: A Cross Country Empirical Study, Cambridge, MA: MIT Press.

Bertotti, G., Mayergoyz, I.D. (eds) (2006): The Science of Hysteresis, Vols I-III, Oxford: Academic Press.

Blanchard, O.J. (2005): European unemployment: the evolution of facts and ideas, MIT Department of Economics Working Paper No. 05-24.

Blanchard, O.J., Leigh, D. (2013): Growth forecast errors and fiscal multipliers, International Monetary Fund Working Paper, WP/13/1, Washington, DC.

Blanchard, O.J., Summers, L.H. (1986a): Hysteresis and the European unemployment problem, National Bureau of Economic Research Working Paper No. 1950, June.

Blanchard, O.J., Summers, L.H. (1986b): Hysteresis in unemployment, National Bureau of Economic Research Working Paper No. 2035, October.

Blanchard, O.J., Dell'Ariccia, G., Mauro, P. (2010): Rethinking macroeconomic policy, International Monetary Fund Position Note, SPN/10/03, Washington, DC.

Blinder, A.S. (1987): Keynes, Lucas and scientific progress, in: American Economic Review, 77(2), $130-136$.

Carlin, W., Soskice, D. (1990): Macroeconomics and the Wage Bargain, Oxford, UK: Oxford University Press.

Cerra, V., Saxena, S.C. (2008): Growth dynamics: the myth of economic recovery, in: American Economic Review, 98(1), 439-457.

Colander, D., Follmer, H., Haas, A., Goldberg, M.D., Juselius, K., Kirman, A., Lux, T., Sloth, B. (2009): The financial crisis and the systemic failure of academic economics, Mimeo, Dahlem, Department of Economics, University of Copenhagen.

Cross, R. (1980): Aggregate demand and the natural rate of unemployment, Department of Economics Discussion Paper No. 8008, University of St. Andrews, November.

Cross, R. (1993): On the foundations of hysteresis in economic systems, in: Economics and Philosophy, 9(1), 53-74.

Cross, R., Lang, D. (2011): The NAIRU: still not an interesting rate of unemployment, in: Intervention, 8(2), 317-340.

Cross, R., Grinfeld, M., Lamba, H. (2009): Hysteresis and economics, in: IEEE Control Systems Magazine, 29(1), 30-43, February.

Darby, J., Wren-Lewis, S. (1993): Is there a cointegrating vector for UK wages?, in: Journal of Economic Studies, 20(1/2), 87-115.

Darby, J., Cross, R., Piscitelli, L. (2006): Hysteresis and unemployment: a preliminary investigation, in: Bertotti, G., Mayergoyz, I.D. (eds), The Science of Hysteresis, Vol. I, Oxford: Academic Press, 667-699.

DeLong, B., Summers, L.H. (2012): Fiscal policy in a depressed economy, Mimeo, 20 March, U.C. Berkeley and Harvard University.

Dixit, A. (1992): Investment and hysteresis, in: Journal of Economic Perspectives, 6(1), 107-132.

Dow, C. (1998): Major Recessions: Britain and the World 1920-1995, Oxford: Oxford University Press.

Ewing, A.W. (1939): The Man of Room 40: The Life of Sir Alfred Ewing, London: Hutchinson.

Ewing, J.A. (1881): On the production of transient electric currents in iron and steel conductors by twisting them when magnetised or by magnetising them when twisted, in: Proceedings of the Royal Society of London, 33, 21-23.

Farmer, R.E.A. (2013): The natural rate hypothesis: an idea past its sell-by date, in: Bank of England Quarterly Bulletin, Q3, 244-256.

Friedman, M. (1968): The role of monetary policy, in: American Economic Review, 58(1), 1-17.

Friedman, M. (1993): The 'plucking' model of business fluctuations revisited, in: Economic Inquiry, 31(2), 171-177.

Göcke, M. (2002): Various concepts of hysteresis applied in economics, in: Journal of Economic Surveys, 16, 167-188.

Hamilton, J.D. (1989): A new approach to the economic analysis of nonstationary time series and the business cycle, in: Econometrica, 57(2), 357-384.

Hargreaves Heap, S.P. (1980): Choosing the wrong 'natural' rate: accelerating inflation or decelerating employment and growth, in: Economic Journal, 90(359), 611-620. 
IMF (International Monetary Fund) (2012): World Economic Outlook, October, Washington, DC. Jenkinson, T.J. (1988): The NAIRU: statistical fact or theoretical straitjacket? in: Cross, R. (ed.), Unemployment, Hysteresis and the Natural Rate Hypothesis, Oxford: Blackwell, 365-377.

Kahneman, D., Tversky, A. (1979): Prospect theory: an analysis of decisions under risk, in: Econometrica, 47, 263-291.

Keynes, J.M. (1934): Poverty in plenty: is the economic system self-adjusting? in: The Listener, 21 November, London: BBC.

Keynes, J.M. (1936): The General Theory of Employment, Interest and Money, London: Macmillan.

Kindleberger, C.P., Aliber, A. (2005): Manias, Panics and Crashes: A History of Financial Crises, 5th edn, Hoboken, NJ: Wiley.

Kindleberger, C.P., Aliber, A. (2011): Manias, Panics and Crashes: A History of Financial Crises, 6th edn, Hoboken, NJ: Wiley.

Kirman, A. (1992): Whom or what does the representative agent represent? in: Journal of Economic Perspectives, 6(2), 117-136.

Kirman, A. (2011): The economic entomologist, in: Erasmus Journal for Philosophy and Economics, 4(2), 42-66.

Krasnosel'skii, M.A., Pokrovskii, A.V. (1989): Systems with Hysteresis, Berlin: Springer-Verlag.

Layard, R., Nickell, S.J., Jackman, R. (1991): Unemployment: Macroeconomic Performance and the Labour Market, Oxford: Oxford University Press.

Leijonhufvud, A. (1973): Life among the Econ, in: Western Economic Journal, 11(3), 327-337.

Lucas, R. (2009): In defence of the dismal science, in: The Economist, 6 August, London, UK, URL: www.economist.com/node/14165405.

Marshall, A. (1890): Principles of Economics, 1st edn, London: Macmillan.

Mayergoyz, I.D. (1991): Mathematical Models of Hysteresis, New York: Springer-Verlag.

McGregor, A. (1978): Unemployment duration and re-employment probability, in: Economic Journal, 88(4), 693-706.

Nickell, S.J. (1987): Why is wage inflation in Britain so high? in: Oxford Bulletin of Economics and Statistics, 49(1), 103-128.

Nickell, S.J., Nuziata, L., Ochel, W. (2005): Unemployment in the OECD since the 1960s: what do we know? in: Economic Journal, 115(1), 1-27.

Oi, W.Y. (1962): Labour as a quasi-fixed factor, in: Journal of Political Economy, 70(6), 538-555.

Phelps, E.S. (1967): Phillips curves, expectations of inflation and optimal unemployment over time, in: Economica, 34(3), 254-281.

Phelps, E.S. (1972): Inflation Policy and Unemployment Theory, London: Macmillan.

Phelps, E.S. (1995): The structuralist theory of employment, in: American Economic Review, 85(2), 226-231.

Piscitelli, L., Grinfeld, M., Lamba, H., Cross, R. (1999): Exit-entry decisions in response to aggregate shocks, in: Applied Economics Letters, 6, 569-572.

Preisach, F. (1935): Uber die magnetische nachwirkung, in: Zeitschrift für Physik, 94, 277-302.

Solow, R.M. (1987): Unemployment: getting the questions right, in: Economica, 53, S23-S34.

Staiger, D., Stock, J.H., Watson, M.W. (1997): The NAIRU, unemployment and monetary policy, in: Journal of Economic Perspectives, 11(1), 33-49. 